\title{
Selection of Social Media Applications for Ubiquitous Learning using Fuzzy TOPSIS
}

\author{
Caitlin Sam ${ }^{1}$, Nalindren Naicker ${ }^{2}$, Mogiveny Rajkoomar $^{3}$ \\ Department of Information Systems, Durban University of Technology, Durban, KwaZulu-Natal
}

\begin{abstract}
The exponential advancements in Information and Communications Technology has led to its prevalence in education, especially with the arrival of COVID-19. Ubiquitous learning (u-learning) is everyday learning that happens irrespective of time and place and it is enabled by m-learning, elearning, and social computing such as social media. Due to its popularity, there has been an expansion of social media applications for $u$-learning. The aim of this research paper was to establish the most relevant social media applications for ulearning in schools. Data was collected from 260 respondents, which comprised learners, and instructors in high schools who were asked to rank 14 of the top social media applications for ubiquitous learning. Fuzzy TOPSIS (Technique for Order Preference by Similarity to Ideal Solution) was the method employed for the ranking of the 14 of the most popular social media applications using 15 education requirements, 15 technology criteria, and 260 decision makers. The simulation was implemented on MATLAB R2020a. The results showed that YouTube was the most likely social media application to be selected for u-learning with a closeness coefficient of 0.9188 and that Viber was the least likely selected social media application with a closeness coefficient of 0.0165 . The inferences of this research study will advise researchers in the intelligent decision support systems field to reduce the time and effort made by instructors and learners to select the most beneficial social media application for u-learning.
\end{abstract}

Keywords-Social media applications; Ubiquitous learning; fuzzy Technique for Order of Preference by Similarity to Ideal Solution (TOPSIS); Multiple criteria decision-making tools

\section{INTRODUCTION}

Ubiquitous learning (u-learning) is a learning paradigm which advocates the employment of ubiquitous computing devices to retrieve learning and teaching resources via. wireless networks [1]. It is evident from the extant literature that education has been indelibly transformed by technology. It enhances and simulates the traditional learning experience, developing instructor and learner behaviour, and creates opportunities for discovery and experimentation [2-4]. As technologies and online tools have progressed, social media has become an essential tool for facilitating applied learning activities [2]. Social media relates to computer-based technology that enables the dissemination of information, thoughts, and ideas through the construction of virtual communities and networks [5]. Social media technologies offer instructors a means to involve learners with selfregulated and time-on-task learning $[2,6,7]$. Generally, social media affords avenues for end-users to communicate and to cultivate connections regardless of geographical barriers and time constraints [2]. In South Africa (SA) alone, out of the
36,4 million people that are internet users, 22 million have social media accounts [8].

School-based learners are captivated by social media [9]. Studies have explained that the adolescent brain has a more sensitive nucleus accumbens and this makes their brain's reward circuitry more activated by social media. Research has also found that the region of the brain linked to visual attention and the social brain are stimulated by social media [10]. An interesting observation is that youth between the ages thirteen and eighteen comprise no less than a fifth of the twelve million Facebook users in SA [9, 11]. A survey revealed that individuals between the ages twelve to nineteen spend ordinary 16,6 hours each week on social networking websites [12]. Recently, there has been a drive towards ulearning with more and more schools being fixated on student centered learning. U-learning is a popular platform to support student centered learning [13]. Furthermore, in unprecedented times such as Covid-19 u-learning is considered as the platform normal teaching and learning practice.

Therefore, there exists a need to support school-based decision makers on which social media applications are most appropriate for $u$-learning. Much scope exists to address this research gap. A novel application of fuzzy TOPSIS (Technique for Order Preference by Similarity to Ideal Situation) will be used to support decision making on the selection of social media applications for u-learning.

Section 2 discusses the literature review of the top social media applications employed for u-learning, the main technology criteria and education requirements for ranking social media applications for u-learning, and introduces the multi-criteria decision-making tool fuzzy TOPSIS. Section 3 presents the materials and methods employed, while Section 4 discusses the results of fuzzy TOPSIS generated. Section 5 concludes the study.

\section{LITERATURE REVIEW}

The various features of social media have given rise to a myriad of platforms which can be classified as media sharing tools, social networking tools, experience and resource sharing tools and communication tools [14].

Learners of today have a lot of experience with photo and video-sharing media like YouTube $[15,16]$. YouTube facilitates a constructivist classroom which incorporates learning tools for learners actively produce their own learning encounters through creating and viewing videos; and educators can employ these learning tools to meaningfully engage learners $[15,16]$. 
Facebook has collaborative and social characteristics that encourage active participation and social networking of teachers and learners [15]. Facebook has over one billion users and it permits users to share articles, pictures, videos, music, videos, and users' opinions and thoughts. The use of Facebook as a teaching and learning tool has steadily increased over the years [15].

WhatsApp is a cross-application instant messaging service with one and a half billion active users globally [17, 18]. WhatsApp enables end-users to share image, text, video, and voice messages, and to make voice calls and video calls. The differentiation and ubiquity of WhatsApp, has interested a host of studies in various educational research areas [17, 19]. Academic advantages comprise teacher availability, better accessibility of learning materials, and learning extension beyond class hours, peer collaboration, and peer assessment $[17,20]$. As an assessment tool, WhatsApp can maintain the anonymity of the learner in the group chat whilst allowing the teacher to read all responses [17].

Facebook Messenger is standalone instant messaging application which was originally part of the Facebook Chat. Facebook Messenger's use in education has rarely been documented but there are several features of the application that can be used in education such as generating attractive posts with videos, text, and images; sharing web content; generating and sharing infographics; posting social proof of learner's success stories to engage prospects; organising contests to entice learners to engage with content; and inspiring an online learning community [21].

WeChat is a text communication and voice messaging service application. The study with Shi and Luo [22] discussed the WeChat teaching platform which facilitated the communication between teachers and learners. Such communication made ubiquitous learning feasible for university students. Furthermore, the study proved that the WeChat teaching platform efficiently developed students' translation competence and facilitated communication in translation teaching [23]. Instagram allows users to edit images and videos with digital filters and asynchronously share and publish images and videos. Additionally, Instagram affords Instagram Stories which publishes time-limited content [24]. The key educational application of Instagram is sharing images or videos for analysis or reference by learners. Other educational affordances of Instagram are supporting direct communication between learners and teachers, facilitating communication, promoting collaboration, posting relevant videos and articles to improve the learning experience [24]. Studies into Instagram for education zone into aspects such as its employment in library contexts and in health and medicine [24].

TikTok has over 1 billion users with most users being between the 14 to 30 age group. Due to the application being very popular in India, EduTok was launched to assist Mathematics and English teaching. Pedagogical affordances of TikTok include motivational influence, delivery of realistic experiences, control and review of content, and engagement of learners as creators [25].
QQ is a powerful communication tool that has proved to support numerous learners with online learning, ensure timeous learner feedback, and active interaction between teachers and learners. The QQ group video allows for synchronous and asynchronous teaching where learners can respond on the video call. Teachers can share their computer screen with learners, which enables learners to learn quickly and conveniently [26].

QZone is a multimedia (audio, image, video, text, etc.) weblog fused with instant message software. It has a userfriendly interface and allows resource access with sharing needs permission. The use of Qzone in the teaching and learning of English has been reported in many studies where the application motivated peer feedback, fulfilled instructional feedback, stimulated in-depth communication, and accelerated learning resource sharing [27-29]. Qzone has no limitation of storage, words, and length, and fulfils the requirements of text editing and processing for various specific purposes [30].

Reddit is the most widespread online content aggregator in the world. Users can publish content, down-vote or up-vote content they dislike or like, and comment on posts. Reddit uses a ranking algorithm to make the most up-voted content more visible in the list of posts [31]. Educational stakeholders can contribute to reflective, meaningful, and stimulating discussions about research, educational policy, politics, research, and technology. Reddit offers teachers and learners a practical platform to engage with educational content in a way that is inquiry-based, open to numerous strategies and engaging [31, 32].

Snapchat's main demographic comprises of millennials. Snapchat is a multimedia sharing and mobile photo messaging. Users can generate Snapchat Stories merging text and visual elements making the application attractive for literacy purposes and multimodal composition [17, 33].

Twitter is a microblogging social media application, which has been found to promote collaborative learning and participation hence transcending traditional classrooms in various studies [34, 35]. Studies also reflected that Twitter was most used for assessment and communication purposes. The most beneficial uses of Twitter included teachers sending homework assignments, test deadlines, and important course information, and facilitating peer interaction [34].

Pinterest is an application for organising, harvesting, sharing, and re-sharing images with comments or updates through republishing. The pedagogical value of Pinterest mostly depends on searching for, organizing, and incorporating digital sources into projects $[17,36]$. From a teacher's perspective, Pinterest provides an opportunity for the creation and sense making of instructional resources [17, 37].

Viber is a Voice over IP and an instant messaging application. Users can exchange videos, images, and audio media messages. The study by Farahmand [38] revealed that Viber provided an attractive environment for learners, enhanced communication, improved human interaction, and improved learning [38].

Each apposite social media application for u-learning has numerous characteristics and features, which can be largely 
considered as education requirements and technology criteria that need to be investigated by the instructor for it to correlate with the outcomes of the lesson [1]. According to literature, general technology criteria of u-learning include: scalability to accommodate various class sizes, ease of use, the technical support and support availability and hypermediality; cost of use and required equipment [39]; user-focused participation and accessibility standards [40], embedding or integration within an Learning Management System, computer operating system and browser and need for additional downloads; offline access, mobile access, and mobile functionality; privacy, data protection and rights [41]. The typical education requirements of ubiquitous learning that need to be considered are collaboration via. synchronous and asynchronous opportunities, user accountability and diffusion relating to the users' comfort with the tool; teacher facilitation, learning customisation and learning analytics; metacognitive engagement, higher order thinking, and enhancement of cognitive tasks [41]; instructor/learner attitude and beliefs, instructor/learner motivation and incentive, and alignment with learning outcomes and objectives (usefulness) [42].

Therefore, selecting social media applications for $\mathrm{u}$ learning would require a multi-criteria decision-making tool. Existing literature has proved the efficiency of using fuzzy TOPSIS for selecting social media applications with multiple criteria [42, 43]. Fuzzy TOPSIS is a technique first developed by Hwang and Yoon [44], which is employed to systematically and objectively evaluate various alternatives against multiple selected criteria to solve multi-criteria decision-making (MCDM) problems [45]. The rationale of fuzzy TOPSIS is that the solution that minimises the cost criteria and maximises the benefit criteria will be denoted by an alternative with the smallest distance from the positive ideal solution (PIS). Alternately, the solution that minimises the benefit criteria and maximises the cost criteria will be denoted by an alternative with the largest distance from the negative ideal solution (NIS) [46]. Since human opinions are vague and cannot be quantified, classical TOPSIS cannot be applied as it assigns crisp numerical data to the alternative's performance ratings and criteria weights [47]. Thus, the fuzzy set theory has been incorporated in many MCDM approaches, namely, TOPSIS [48].

In recent times, fuzzy TOPSIS techniques and its functions have been covered extensively by more scholars [49]. This paper will use fuzzy TOPSIS to select social media applications for u-learning in high schools.

\section{RESEARCH METHOD}

\section{A. Population}

The target population was school-based instructors and learners from the eThekwini Region, namely, Pinetown District and Umlazi District in KwaZulu Natal, South Africa. As per the March 2020 Schools Masterlist Data derived from the Department of Basic Education in South Africa [50] the study's population size was approximately $129 \quad 421$ individuals which comprised 4853 school-based instructors and 124388 learners. For clarification of the target population, the school-based instructors and learners were treated as a single population. Thus, the decision makers were inclusively the learners and instructors that used social media applications for u-learning.

\section{B. Sample}

In accordance with the guidelines set by Sekaran and Bougie [51], as the target population size of the study was approximately 129421 (Department of Basic Education, 2020), the sample size was 384 respondents. However, the response rate was $67,71 \%$ with the total number of responses received being 260. According to literature, the goal of researchers conducting a survey questionnaire should be approximately $60 \%$ [52]. Thus, the response rate of the current study was acceptable.

\section{Questionnaire}

To collect the dataset, a link to the survey questionnaire was forwarded to respondents' devices. Online survey questionnaires on Google Forms delivered a user-friendly interface on all respondents' devices and a cost-effective and time-efficient data collection. When compared to other survey-generating platforms, an unlimited number of matrixformatted questions could be generated on Google Forms. The questionnaire comprised closed ended questions using a Likert scale where the respondent chose one suitable answer for each question. The possible answers were 'very poor', 'poor', 'fair', 'good', or 'very good' and 'not sure'. The 'not sure' option was presented to respondents who were unfamiliar with certain social media applications. The first part of the questionnaire consisted of questions pertaining to the respondents' demographic data. The questions involved education requirements and technology criteria resulting from the existing literature that is important to the social media diffusion management in school-based u-learning. The 30 most commonly occurring education requirements (15) and technology criteria (15) were chosen. Table I shows a snippet of the survey questionnaire.

ADAPTABILITY: the social media application provides personalized learning, which aims to give efficient, effective, and customized learning paths to attract each learner.

TABLE I. SNIPPET OF SURVEY QUESTIONNAIRE GENERATED ON GOOGLE FORMS

\begin{tabular}{|l|l|l|l|l|l|l|}
\hline & $\begin{array}{l}\text { Very } \\
\text { Good }\end{array}$ & Good & Fair & Poor & $\begin{array}{l}\text { Very } \\
\text { Poor }\end{array}$ & $\begin{array}{l}\text { Not } \\
\text { Sure }\end{array}$ \\
\hline Facebook & $\square$ & $\square$ & $\square$ & $\square$ & $\square$ & $\square$ \\
\hline WhatsApp & $\square$ & $\square$ & $\square$ & $\square$ & $\square$ & $\square$ \\
\hline YouTube & $\square$ & $\square$ & $\square$ & $\square$ & $\square$ & $\square$ \\
\hline $\begin{array}{l}\text { Facebook } \\
\text { Messenger }\end{array}$ & $\square$ & $\square$ & $\square$ & $\square$ & $\square$ & $\square$ \\
\hline Instagram & $\square$ & $\square$ & $\square$ & $\square$ & $\square$ & $\square$ \\
\hline TikTok & $\square$ & $\square$ & $\square$ & $\square$ & $\square$ & $\square$ \\
\hline QQ & $\square$ & $\square$ & $\square$ & $\square$ & $\square$ & $\square$ \\
\hline QZone & $\square$ & $\square$ & $\square$ & $\square$ & $\square$ & $\square$ \\
\hline Reddit & $\square$ & $\square$ & $\square$ & $\square$ & $\square$ & $\square$ \\
\hline Pinterest & $\square$ & $\square$ & $\square$ & $\square$ & $\square$ & $\square$ \\
\hline WeChat & $\square$ & $\square$ & $\square$ & $\square$ & $\square$ & $\square$ \\
\hline SnapChat & $\square$ & $\square$ & $\square$ & $\square$ & $\square$ & $\square$ \\
\hline Twitter & $\square$ & $\square$ & $\square$ & $\square$ & $\square$ & $\square$ \\
\hline Viber & $\square$ & $\square$ & $\square$ & $\square$ & $\square$ & $\square$ \\
\hline
\end{tabular}


The data was analysed and synthesised using fuzzy TOPSIS programmatically on MATLAB R2020a.

\section{Fuzzy TOPSIS Method}

The fuzzy TOPSIS method assesses various alternatives against the selected criteria. In the TOPSIS method, the best alternative is typified by a calculated distance that is closest to the Fuzzy Positive Ideal Solution (FPIS) and furthest from the Fuzzy Negative Ideal Solution (FNIS) [53]. An FPIS involves alternatives with the best performance values and the FNIS involves alternatives with the worst performance values. In fuzzy TOPSIS linguistic variables are utilised to describe all the ratings and weights which in turn are expressed by fuzzy numbers [54]. The fuzzy set theory illustrates a triangular fuzzy number $(\mathrm{TFN})$ as a triplet $(\mathrm{a} ; \mathrm{b} ; \mathrm{c})$ where:

$F(x)$ can be expressed as:

$\mu_{\tilde{A}}(X)=\left\{\begin{array}{c}\frac{x-a}{b-a}, a \leq x \leq b \\ \frac{c-x}{c-b}, b \leq x \leq c \\ 0, \text { otherwise }\end{array}\right.$

The fuzzy triplets a, b and c are real numbers and $a<b<$ $c$ [53]. There are a series of steps as outlined below that must be adhered to when conducting the fuzzy TOPSIS algorithm [54].

\section{E. Steps of the Fuzzy TOPSIS method}

The steps below illustrate the fuzzy rating and importance weight of the $k^{\text {th }}$ decision maker, about the $i^{\text {th }}$ alternative on $j^{\text {th }}$ criterion [53].

Step 1: Assignment of ratings to the alternatives and the criteria.

Assume that there are $m$ possible alternatives called $A=\left\{A_{1} ; A_{2} ; \ldots ; A_{m}\right\}$ which must be evaluated against $n$ criteria, $C=\left\{C_{1} ; C_{2} ; \ldots ; C_{n}\right\}$. Criteria weights are represented by $w_{g}(g=1,2, \ldots, n)$. Each decision maker's $D_{k}(k=$ $1,2, \ldots, k)$ ratings for each alternative $A_{i}(i=1,2, \ldots, m)$ regarding criteria $C_{j}(j=1,2, \ldots, n)$ are indicated by $\tilde{R}_{k}=\tilde{x}_{i g k}$ $\tilde{R}$ with the membership function $\mu_{\tilde{R}_{k}}(x)$.

The fuzzy ratings for the criteria by decision makers are shown in the Table II.

The fuzzy ratings for the alternatives are shown in the Table III.

Step 2: Computation of aggregated fuzzy ratings for the alternatives and the criteria.

- If the importance weight and fuzzy rating of the decision maker $k$ are [53]:

$\widetilde{w}_{i g k}=\left(w_{g k 1}, w_{g k 2}, w_{g k 3}\right)$

and $\tilde{x}_{i g k}=\left(a_{i g k}, b_{i g k}, c_{i g k}\right)$,

$i=1,2, \ldots m, g=1,2, \ldots, n$

respectively, then the aggregated fuzzy ratings $\tilde{x}_{i j k}$ of each alternative relating to each criterion is presented as: $\tilde{x}_{i j k}=\left(a_{i g}, b_{i g}, c_{i g}\right)$

where: $a_{i g}=\min _{k}\left\{a_{i g k}\right\}$

$b_{i g}=\frac{1}{k} \sum_{k=1}^{k} b_{i g k}$

$c_{i g}=\max _{k}\left\{c_{i g k}\right\}$

- The aggregated fuzzy weights $\left(\widetilde{w}_{i j}\right)$ of each criterion is calculated as

$\widetilde{w}_{i g}=\left(w_{g 1}, w_{g 2}, w_{g 3}\right)$

where: $w_{g 1}=\min _{k}\left\{w_{g k 1}\right\}, w_{g 2}=\frac{1}{k} \sum_{k=1}^{k} w_{j k 2}$,

$w_{g 3}=\max _{k}\left\{w_{j k 3}\right\}$

Step 3: Computation and normalisation of the fuzzy decision matrix.

The fuzzy decision matrix is computed as such:

$\widetilde{D}=\begin{gathered}A_{1} \\ A_{2} \\ A_{m}\end{gathered}\left(\begin{array}{cccc}\tilde{x}_{11} & \tilde{x}_{12} & \ldots & \tilde{x}_{1 n} \\ \tilde{x}_{21} & \tilde{x}_{22} & \ldots & \tilde{x}_{2 n} \\ \tilde{x}_{m 1} & \tilde{x}_{m 2} & \ldots & \tilde{x}_{m n}\end{array}\right)$

$\widetilde{W}=\left(\widetilde{w}_{1}, \widetilde{w}_{2}, \ldots, \widetilde{w}_{n}\right)$

The various criteria scales are normalised into a comparable scale. The normalised fuzzy decision matrix is $\widetilde{\boldsymbol{R}}$ and is presented as:

$\widetilde{R}=\left[\tilde{r}_{i g}\right] m \times n, i=1,2, \ldots, m ; g=1,2, \ldots, n$

thus, the benefit criteria: $\overline{\boldsymbol{r}}_{i g}=\frac{a_{i g}}{c_{g}^{+}}, \frac{\boldsymbol{b}_{i g}}{\boldsymbol{c}_{g}^{+}}, \frac{\boldsymbol{c}_{\boldsymbol{g}}}{\boldsymbol{c}_{g}^{+}}$

where: $\boldsymbol{c}_{\boldsymbol{g}}^{+}=\boldsymbol{m a x}_{\boldsymbol{i}} \boldsymbol{c}_{\boldsymbol{i g}}$ of the benefit criteria (14)

and for cost criteria: $\tilde{\boldsymbol{r}}_{i g}=\frac{\overline{\boldsymbol{a}}_{j}}{\boldsymbol{c}_{i j}}, \frac{\overline{\boldsymbol{a}}_{j}}{\boldsymbol{b}_{i j}}, \frac{\overline{\boldsymbol{a}}_{j}}{\boldsymbol{a}_{i j}}$

where: $\overline{\boldsymbol{a}}_{\boldsymbol{j}}=\boldsymbol{m i n i m i m}_{\boldsymbol{i}} \boldsymbol{a}_{\boldsymbol{i g}}$ of the cost criteria

TABLE II. LINGUISTIC TERMS FOR CRITERIA

\begin{tabular}{|l|l|}
\hline Linguistic term & Triangular fuzzy numbers \\
\hline Very poor $(\mathrm{VP})$ & $(1,1,3)$ \\
\hline Poor $(\mathrm{P})$ & $(1,3,5)$ \\
\hline Fair $(\mathrm{F})$ & $(3,5,7)$ \\
\hline Good $(\mathrm{G})$ & $(5,7,9)$ \\
\hline Very good $(\mathrm{VG})$ & $(7,9,9)$ \\
\hline
\end{tabular}

TABLE III. LINGUISTIC TERMS FOR Alternatives

\begin{tabular}{|l|l|}
\hline Linguistic term & Triangular fuzzy numbers \\
\hline Very poor (VP) & $(1,1,3)$ \\
\hline Poor (P) & $(1,3,5)$ \\
\hline Fair (F) & $(3,5,7)$ \\
\hline Good (G) & $(5,7,9)$ \\
\hline Very good (VG) & $(7,9,9)$ \\
\hline
\end{tabular}


Step 4: Computation of the weighted normalised matrix

The weighted normalised fuzzy decision matrix $\widetilde{\boldsymbol{v}}_{\boldsymbol{i j}}$ is derived by:

$\widetilde{V}=\left[\widetilde{v}_{i j}\right]_{m \times n} i=1,2, \ldots, n ; j=1,2, \ldots, m$

where: $\widetilde{\boldsymbol{V}}_{i j}=\tilde{\boldsymbol{r}}_{i j} \times \widetilde{\boldsymbol{w}}_{j}$

Step 5: Computation of the FPIS $\left(\boldsymbol{A}^{+}\right)$and FNIS $\left(\boldsymbol{A}^{-}\right)$

The FPIS of the alternatives are computed as:

$A^{+}=\left(\widetilde{v}_{1}^{+}, \widetilde{v}_{2}^{+}, \ldots, \widetilde{v}_{m}^{+}\right)$

where: $v_{i}^{+}=\max _{i}\left\{v_{i g 3}\right\}$,

$g=1,2, \ldots, n ; i=1,2, \ldots, m$

and the FNIS of the alternatives are computed as:

$A^{-}=\left(\tilde{v}_{1}^{-}, \tilde{v}_{2}^{-}, \ldots, \tilde{v}_{m}^{-}\right)$

where: $\tilde{v}_{j}^{-}=\min _{i}\left\{v_{i g 1}\right\}$,

$g=1,2, \ldots, n ; i=1,2, \ldots, m$

Step 6: Calculation of the distance of each alternative to get the $A^{+}$matrix and $A^{-}$matrix

The distance $\left(d^{+}, d^{-}\right)$of the $A^{+}$and the $A^{-}$from each weighted alternative $i=1,2, \ldots, m$ is calculated using formula:

$d(\bar{a} \bar{b})=\sqrt{\frac{1}{3}\left[\left(a-a^{\prime}\right)^{2}+\left(b-b^{\prime}\right)^{2}+\left(c-c^{\prime}\right)^{2}\right]}$

Step 7: Calculating the distance of each weighted alternative

The sum of the distance of each weighted alternative is calculated by:

$d_{i}^{+}=\sum_{i=1}^{m} d_{v}\left(\tilde{v}_{i g}, \tilde{v}_{i g}^{+}\right), i=1,2, \ldots, m ;$

$g=1,2, \ldots, n$

$d_{i}^{-}=\sum_{i=1}^{m} d_{v}\left(\tilde{v}_{i g}, \tilde{v}_{i g}^{-}\right), i=1,2, \ldots, m ; g=1,2, \ldots, n$

Step 8: Computation of the closeness coefficient $\left(C C_{i}\right)$ of each alternative

$C C_{i}$ signifies the distances to the FNIS and the FPIS, simultaneously. The calculation of each alternative's $C C_{i}$ is as follows:

$\left(C C_{i}\right)=\frac{d_{1}^{-}}{d_{1}^{-}+d_{1}^{+}}, i=1,2, \ldots, m$

Step 9: Ranking the alternatives

The ranking order of all the alternatives can be derived from the $C C_{i}$. The closer the $C C_{i}$ is to the FPIS and the farthest it is from the FNIS the better the alternative. This means the higher the $C C_{i}$ the higher the rank of the alternative [54].

\section{F. MATLAB R2020a}

Fuzzy TOPSIS was coded using MATLAB R2020a running on a windows i7 computer. MATLAB ${ }^{\circledR}$ merges a desktop environment set for design processes and iterative analysis with a programming language that articulates array and matrix mathematics directly [55]. The MATLAB code followed a modular programming design. Sub programmes for Weighted normalized fuzzy decision matrix for alternatives; Aggregate Fuzzy Weights for Criteria, Distances, and the final calculation of $C C_{i}$ values were called by a main program. The dataset was read by the code using a 'xlsread' statement. Intermediate matrices were generated in the MATLAB workspace. The results obtained is presented in the next section.

\section{RESULTS AND DISCUSSION}

This section presents the results of the 260 respondents' rating of the social media applications using the criteria for the evaluation of social media applications for u-learning. In this study, criteria comprised the technology criteria and the education requirements. In terms of fuzzy TOPSIS an analysis was conducted using 14 alternatives, and 30 criteria with ratings by 260 decision makers (DM). As the criteria formed the top 30 technology criteria and education requirements, the ratings of the attributes were either Good (G) or Very Good (VG). Thus, their weightings were either $(5,7,9)$ or $(7,9,9)$, respectively. Table IV reflects the weightage of the criteria (C), namely education requirements and technology criteria:

Table IV shows 15 education requirements and 15 technology criteria for selection of social media applications for u-learning. The weightage for each criteria is given in terms of a triangular fuzzy number. The criteria weights will be factored into decision making for the ranking of social media applications for u-learning.

The social media applications were the alternatives in the study and were labelled as per Table $\mathrm{V}$ for the simulation on MATLAB.

The multi-criteria decision making using Fuzzy TOPSIS is applied to rank the set of 14 alternatives as shown in Table V.

Table VI shows an extract of the combined decision matrix for A1 which was Facebook. The decision makers rated the alternatives in terms of linguistic scales.

The linguistic terms were assigned fuzzy numbers. The "Not Sure" option termed "N" was zero-rated as it is not a linguistic term identifiable on fuzzy TOPSIS. The aggregated fuzzy ratings for the alternatives and the criteria were computed. Once combined decision matrix was normalised and multiplied by the criteria weightage, the weighted normalised fuzzy decision matrix was achieved. The FPIS $\left(\mathrm{A}^{+}\right)$and FNIS $\left(\mathrm{A}^{-}\right)$were determined and the distance of each alternative to get the $A^{+}$and $A^{-}$matrix was calculated. Table VII shows the $A^{+}$and $A^{-}$matrix of the Facebook alternative.

The sum of the distance of each weighted alternative was calculated using formula (24) and (25). Thereafter the $\mathrm{CC}_{\mathrm{i}}$ was calculated using formula (26). Table VIII reflects the $\mathrm{CC}_{\mathrm{i}}$ and ranking of each alternative. 
TABLE IV. WEIGHTED ATtRIBUTES OF SOCIAL MEDIA APPLICATIONS FOR UBIQUiTOUS LEARNINC

\begin{tabular}{|l|l|l|l|l|l|}
\hline C\# & Education Requirements & Weightage & C\# & Technology Criteria & Weightage \\
\hline 1. & Ownership of Learning & $(5,7,9)$ & 16. & Operational Stability & $(7,9,9)$ \\
\hline 2. & Adaptability & $(5,7,9)$ & 17. & Fault Tolerance of Technology & $(7,9,9)$ \\
\hline 3. & Quality Assurance & $(5,7,9)$ & 18. & Hypermediality & $(7,9,9)$ \\
\hline 4. & Peer Learning & $(5,7,9)$ & 19. & Multimedia Control & $(7,9,9)$ \\
\hline 5. & Instructional Design & $(5,7,9)$ & 20. & Security of Technology & $(7,9,9)$ \\
\hline 6. & Academic Integrity & $(5,7,9)$ & 21. & Facilitation of e-Content & $(7,9,9)$ \\
\hline 7. & U-learning training factors & $(5,7,9)$ & 22. & Technical Information & $(7,9,9)$ \\
\hline 8. & Archiving/ Repository & $(5,7,9)$ & 23. & Software Characteristics Quality & $(5,7,9)$ \\
\hline 9. & Social Interaction & $(5,7,9)$ & 24. & Ease of Use & $(7,9,9)$ \\
\hline 10. & Curriculum Management & $(7,9,9)$ & 25. & Operating System & $(5,7,9)$ \\
\hline 11. & Facilitation & $(5,7,9)$ & 26. & Browser & $(7,9,9)$ \\
\hline 12. & Learning Analytics & $(5,7,9)$ & 27. & Access on a Mobile Platform & $(5,7,9)$ \\
\hline 13. & Enhancement of Cognitive Tasks & $(5,7,9)$ & 28. & Data Privacy and Ownership & $(7,9,9)$ \\
\hline 14. & Higher Order Thinking & $(5,7,9)$ & 29. & Downloading, Saving and Exporting Data & $(5,7,9)$ \\
\hline 15. & Metacognitive Engagement & $(5,7,9)$ & 30. & Additional Download & $(5,7,9)$ \\
\hline
\end{tabular}

TABLE V. Labelled Social Media APPlications

\begin{tabular}{|l|l|l|l|}
\hline Social Media Application & Alternative (A) & Social Media Application & Alternative (A) \\
\hline Facebook & 1 & QZone & 8 \\
\hline WhatsApp & 2 & Reddit & 9 \\
\hline YouTube & 3 & Pinterest & 10 \\
\hline Facebook Messenger & 4 & WeChat & 11 \\
\hline Instagram & 5 & SnapChat & 12 \\
\hline TikTok & 6 & Twitter & 13 \\
\hline QQ & 7 & Viber & 14 \\
\hline
\end{tabular}

TABLE VI. ASSIGNMENT OF RATINGS To FACEBOOK By DECISION MAKERS

\begin{tabular}{|c|c|c|c|c|c|c|c|c|c|}
\hline \multirow{2}{*}{ Criteria } & \multicolumn{9}{|c|}{ FACEBOOK (A1) } \\
\hline & DM1 & DM2 & DM3 & DM4 & DM5 & DM6 & DM7 & DM8... & DM260 \\
\hline $\mathrm{C} 1$ & $\mathrm{~N}$ & $\mathrm{P}$ & $\mathrm{N}$ & $\mathrm{N}$ & $\mathrm{N}$ & $\mathrm{F}$ & G & $\mathrm{G}$ & G \\
\hline $\mathrm{C} 2$ & $\mathrm{~F}$ & $P$ & VP & $\mathrm{N}$ & $\mathrm{N}$ & G & $\mathrm{F}$ & $\bar{G}$ & G \\
\hline $\mathrm{C} 3$ & $\mathrm{~F}$ & $P$ & $\mathrm{~N}$ & $\mathrm{~N}$ & $\mathrm{~N}$ & $\mathrm{~F}$ & $\mathrm{~F}$ & $\mathrm{~F}$ & VG \\
\hline $\mathrm{C} 4$ & $\mathrm{~N}$ & $\mathrm{P}$ & $\mathrm{N}$ & $\mathrm{N}$ & $\mathrm{N}$ & $\mathrm{F}$ & G & G & $\mathrm{F}$ \\
\hline $\mathrm{C} 5$ & $\mathrm{~N}$ & $P$ & $\mathrm{~F}$ & $\mathrm{~N}$ & $\mathrm{~N}$ & $\mathrm{~F}$ & VG & G & $\mathrm{F}$ \\
\hline C6 & $\mathrm{F}$ & $\mathrm{P}$ & $\mathrm{N}$ & $\mathrm{N}$ & $\mathrm{N}$ & $\mathrm{G}$ & $\mathrm{F}$ & G & VG \\
\hline $\mathrm{C} 7$ & $\mathrm{~N}$ & $P$ & $\mathrm{~N}$ & $\mathrm{~N}$ & $\mathrm{~N}$ & $\mathrm{~F}$ & $\mathrm{~N}$ & G & G \\
\hline $\mathrm{C} 8$ & $\mathrm{~N}$ & $\mathrm{P}$ & $\mathrm{F}$ & $\mathrm{VP}$ & $\mathrm{VP}$ & $\mathrm{G}$ & VG & VG & VG \\
\hline $\mathrm{C} 9$ & $\mathrm{~N}$ & $P$ & $\mathrm{~N}$ & $\mathrm{~N}$ & $\mathrm{~N}$ & $\mathrm{~F}$ & G & G & $\mathrm{F}$ \\
\hline $\mathrm{C} 10 \ldots$ & $\mathrm{N}$ & $\mathrm{N}$ & $\mathrm{F}$ & $\mathrm{N}$ & $\mathrm{N}$ & $\mathrm{G}$ & G & VG & $\mathrm{F}$ \\
\hline $\mathrm{C} 26$ & $\mathrm{G}$ & $\mathrm{N}$ & VG & $\mathrm{N}$ & $\mathrm{VP}$ & G & VG & G & $\mathrm{F}$ \\
\hline $\mathrm{C} 27$ & $\mathrm{G}$ & $\mathrm{N}$ & $\mathrm{VP}$ & $\mathrm{N}$ & $\mathrm{N}$ & VG & VG & $\mathrm{G}$ & G \\
\hline $\mathrm{C} 28$ & $\mathrm{G}$ & $\mathrm{N}$ & $\mathrm{G}$ & $\mathrm{N}$ & $\mathrm{F}$ & VG & VG & VG & VG \\
\hline C29 & G & $\mathrm{N}$ & $\mathrm{N}$ & $\mathrm{N}$ & $\mathrm{N}$ & VG & VG & VG & VG \\
\hline C30 & G & $\mathrm{N}$ & $\mathrm{N}$ & $\mathrm{N}$ & $\mathrm{N}$ & VG & VG & VG & VG \\
\hline
\end{tabular}


TABLE VII. THE FPIS $\left(\mathrm{A}^{+}\right)$AND FNIS $\left(\mathrm{A}^{-}\right)$OF FACEBOOK

\begin{tabular}{|l|l|l|l|l|l|}
\hline Criteria & FPIS $\left(\mathbf{A}^{+}\right)$ & FNIS $\left(\mathbf{A}^{-}\right)$ & Criteria & FPIS $\left(\mathbf{A}^{+}\right)$ & FNIS $\left(\mathbf{A}^{-}\right)$ \\
\hline C1 & 1.4887 & 0.5526 & C16 & 1.2538 & 0.5993 \\
\hline C2 & 1.5578 & 0.5285 & C17 & 0.7616 & 0.4110 \\
\hline C3 & 1.4645 & 0.5008 & C18 & 0.9930 & 1.0621 \\
\hline C4 & 1.2866 & 0.8221 & C19 & 0.8342 & 1.0293 \\
\hline C5 & 1.5405 & 0.5077 & C20 & 0.6425 & 0.6597 \\
\hline C6 & 1.0949 & 0.4680 & C21 & 1.0621 & 0.7236 \\
\hline C7 & 1.4300 & 0.6701 & C22 & 0.7461 & 0.9067 \\
\hline C8 & 1.9274 & 0.0000 & C23 & 0.6580 & 0.6459 \\
\hline C9 & 1.4922 & 0.8894 & C24 25 & 0.7443 & 0.6822 \\
\hline C10 & 1.4783 & 0.5526 & C26 & 0.4473 & 0.9153 \\
\hline C11 & 1.0138 & 0.5665 & C27 & 0.4628 & 0.8894 \\
\hline C12 & 0.9032 & 0.6079 & C28 & 0.9792 \\
\hline C13 & 1.1312 & 0.4197 & C29 & 0.7098 & 0.6908 \\
\hline C14 & 1.3246 & 0.5526 & C30 & 0.6217 \\
\hline C15 & 0.8894 & & \\
\hline
\end{tabular}

TABLE VIII. Closeness Coefficient $\left(\mathrm{CC}_{\mathrm{I}}\right)$ AND RANKING of ALternatives

\begin{tabular}{|l|l|l|}
\hline Ranking \# & Alternative & $\left(\mathbf{C C}_{\mathbf{i}}\right)$ \\
\hline 1 & YouTube & 0.9188 \\
\hline 2 & WhatsApp & 0.8691 \\
\hline 3 & Instagram & 0.4835 \\
\hline 4 & TikTok & 0.3877 \\
\hline 5 & Facebook & 0.3817 \\
\hline 6 & Facebook Messenger & 0.3249 \\
\hline 7 & Pinterest & 0.2801 \\
\hline 8 & SnapChat & 0.2484 \\
\hline 9 & Twitter & 0.2108 \\
\hline 10 & Reddit & 0.1601 \\
\hline 11 & WeChat & 0.1379 \\
\hline 12 & QQ & 0.0720 \\
\hline 13 & QZone & 0.0344 \\
\hline 14 & Viber & 0.0165 \\
\hline
\end{tabular}

Since $\quad C C_{\text {YouTube }}>C C_{\text {WhatsApp }}>C C_{\text {Instagram }}>$ $C C_{\text {TikTok }}>C C_{\text {Facebook } \cdots \text {, YouTube is the preferred social }}$ media platform considering the given criteria. For example, if the criterion 'Ownership of Learning' is explored in relation to YouTube, it is evident that YouTube fulfils all the expectations of the end-user being motivated, engaged and self-directed. According to Husain et al. [58], YouTube allows teachers and learners ubiquitous access on any digital device to videos and content made by subject experts from all around the world that would have otherwise been expensive to acquire. Teachers and learners can learn skills from step-bystep videos made by skilled individuals on YouTube that can be replayed countless of times. YouTube is an unlimited digital library with multimedia tools and is a platform where teachers and learners can make their own videos to display their skills and talents on a global scale. The use of YouTube facilitates for flipped classrooms which allows individuals to take ownership of their learning in a manner that is free and fair to all that want to learn [59]. Regarding Viber, several sources revealed that it has poor messaging services and voice call quality without Wi-Fi connection [60].

\section{CONCLUSION}

Social media has become an integral tool in the affordance of ubiquitous learning for schools, especially in unprecedented times such as COVID-19. According to HelloYes [56], the most used social media applications in South Africa in ranking order are WhatsApp, YouTube, Facebook, FB Messenger, Instagram, Twitter, Pinterest, LinkedIn, Snapchat, Skype, Reddit, TikTok, Tumbler, WeChat, Twitch, and Viber. However, according to Smart Insights [57] Generation Z individuals prefer the following social media applications: 
Facebook, YouTube, WhatsApp, Facebook Messenger, WeChat, Instagram, TikTok, QQ, QZone, Reddit, Snapchat, Twitter, Pinterest, and Viber. This study ranked 14 of the top social media applications at the time using the multiple criteria decision-making tool fuzzy TOPSIS and 30 ubiquitous learning criteria with the 260 decision makers. The results revealed that YouTube proved to be the most significant social media application for ubiquitous learning with a $\mathrm{CC}_{\mathrm{i}}=$ 0,9188 , closely followed by WhatsApp with a $\mathrm{CC}_{\mathrm{i}}=0,8691$. Viber was identified as being the least likely application suitable to ubiquitous learning with a $\mathrm{CC}_{\mathrm{i}}=0,0165$.

A limitation of the current study was that it had to be representative of the high school population in the Pinetown and Umlazi Districts in the province of KwaZulu Natal, South Africa, responses from a large sample population had to be acquired. The opinions of 260 decision makers comprising instructors and learners in high schools was a novel approach that proved to be initially challenging to configure on MATLAB R2020a. An implication of this study is that it contributed to the gap of literature on the use of fuzzy TOPSIS in school-based education and enriched the literature on the application of fuzzy TOPSIS within a South African schooling context. Additionally, given the current pandemic, getting "online now" presents a different focus for decision making around social media platforms as ubiquitous learning tools. Future studies will focus on intelligent decision support systems to reduce the time and effort made by instructors and learners to select the most beneficial social media application for ubiquitous learning.

\section{ACKNOWLEDGMENTS}

Kind acknowledgement to the Durban University of Technology for making funding opportunities and resources available for this research project.

\section{REFERENCES}

[1] C., Sam, N. Naicker, and M. Rajkoomar, Meta-analysis of artificial intelligence works in ubiquitous learning environments and technologies. International Journal of Advanced Computer Science and Applications. Vol. (11), No. (9), 2020, p. 603-613.

[2] J., Purvis, H.M. Rodger, and S. Beckingham, Experiences and perspectives of social media in learning and teaching in higher education. International Journal of Educational Research Open. Vol. (1), 2020, p. 1-17.

[3] M., Chen, Students' perceptions of the educational usage of a Facebook group. Journal of Teaching in Travel and Tourism. Vol. (18), No. (4), 2018, p. 332-348.

[4] D.R., Garrison and H. Kanuka, Blended learning: Uncovering its transformative potential in higher education. Internet and Higher Education. Vol. (7), No. (2), 2004, p. 95-105.

[5] C., Greenhow, S.M. Galvin, and K.B.S. Willet, What should be the role of social media in education? Behavioural and Brain Sciences. Vol. (6), No (2), 2019, p. 178-185.

[6] A. J., Purvis, H.M. Rodger, and S. Beckingham, Engagement or distraction: The use of social media for learning in higher education. Student Engagement and Experience Journal. Vol. (5), No (1), 2016, p. $1-5$.

[7] N., Dabbagh and A. Kitsantas, Personal learning environments, social media, and self-regulated learning: A natural formula for connecting formal and informal learning. Internet and Higher education. Vol. (15), No. (1), 2011, p. 3-8.
[8] Statista. Digital population in South Africa, 2020, Accessed on 30 January 2020; Available from: https://www.statista.com/ statistics/685134/south-africa-digital-population.

[9] Shava, H. and W.T. Chinyamurindi, Determinants of social media usage among a sample of rural South African youth. South African Journal of Information Management. Vol. (20), No. (1), 2018, p. 1-8.

[10] S., Wolpert, Teenage brain on social media: Study sheds light on influence of peers and much more. 2016; Accessed on 30 January 2020; Available from: www.sciencedaily.com/releases /2016/05/ 160531104423.htm.

[11] BusinessTech. These are the biggest social media and chat platforms in 2019. 2019; Accessed on 30 January 2020; Available from: https://businesstech.co.za/news/internet/296752/ these-are-the-biggestsocial-media-and-chat-platforms-in-2019/.

[12] J., Lu, Q. Hao, and M. Jing, Consuming, sharing, and creating content: How young students use new social media in and outside school. Computers in Human Behaviour. Vol. (64), 2016, p. 55-64.

[13] D., Jaiswal, New approaches in e-learning: E-learning, m-learning and u-learning. Scholarly Research Journal for Interdisciplinary Studies. Vol. (1), No. (2), 2012, p. 197-203.

[14] G.E., Zgheib and N. Dabbagh, Social media learning activities (SMLA): Implications for design. Online Learning. Vol. (24), No. (1), 2020, p. 50-66.

[15] M., Mei, and L. Yeo, Social media and social networking applications for teaching and learning. European Journal of Science and Mathematics Education. Vol (2), No. (1), 2014, p. 53-62.

[16] R., Mullen and L. Wedwick, Avoiding the digital abyss: Getting started in the classroom with youtube, digital stories and blogs. Clearing house: A Journal of Educational Strategies, Issues and Ideas, 2008. Vol. (82), No. (2), 2008, p. 66-69.

[17] S., Manca, Snapping, pinning, liking, or texting: Investigating social media in higher education beyond Facebook. The Internet and Higher Education. Vol. (44), 2020, p. 1-13.

[18] V., Sigurdsson, R.V., Menon, A.G., Hallgrímsson, N.M., Larsen, \& A., Fagerstrøm. Factors affecting attitudes and behavioral intentions toward in-app mobile advertisements. Journal of Promotion Management, Vol. (24), No. (5), 2018, pp 694-714.

[19] C., Pimmer and P. Rambe, The inherent tensions of "instant education": A critical review of mobile instant messaging. The International Review of Research in Open and Distance Learning. Vol. (19), No. (5), 2018, p. 218-237.

[20] D., Bouhnik and M. Deshen, WhatsApp goes to school: Mobile instant messaging between teachers and students. Journal of Information Technology Education: Research. Vol. (13), No. (1), 2014, p. 217-231.

[21] P., Smutny and P. Schreiberova, Chatbots for learning: A review of educational chatbots for the Facebook Messenger. Computers and Education. Vol. 151, 2020, p. 1-11.

[22] S., Shi and G. Luo, Application of WeChat teaching platform in interactive translation teaching. International Journal of Emerging Technologies in Learning. Vol. 11, No. (9), 2016, p. 71-75.

[23] M. G., Elyazgi, et al., Evaluating the factors influencing e-book technology acceptance among school children using TOPSIS technique. Journal of Soft Computing and Decision Support Systems. Vol. (3), No. (2), 2016, p. 11-25.

[24] M. N. K., Boulos, D.M. Giustini, and S. Wheeler, Instagram and Whatsapp in health and healthcare: An overview. Future Internet. Vol. (8), No. (37), 2016, p. 1-14.

[25] CommonwealthofLearning. Importance of TikTok type videos for learning, 2020, Accessed on 20 January 2020; Available from: https://www.col.org/news/col-blog/importance-tiktok-type-videoslearning.

[26] G., Nan, Application of QQ Classroom in modern university education. Advances in Higher Education. Vol. 4, No. (5), 2020, p. 57-59.

[27] X.P., Wen and W.B. Lai, The application of Qzone in middle school English teaching. The Teaching of Politics. Vol. (12), 2012, p. 145-146.

[28] X.J., Wang, Using Qzone in the process of implementing English language teaching methodology course. Journal of Hubei University of Education. Vol. 26, No. (7), 2009, p. 114-115. 
[29] Q.J., Du, On course design of business English teaching based on QQ platform. Overseas English. Vol. (7), No. (1), 2013, p. 106-108.

[30] G., Xianwei, M., Samuel, and A. Asmawi, Qzone weblog for critical peer feedback to improve business english writing: A case of chinese undergraduates. The Turkish Online Journal of Educational Technology. Vol. 15, No. (3), 2016, p. 131-140.

[31] R.P., Tannebaum, Reddit and the social studies: Exploring the r/democratic curriculum. The Social Science. Vol. (109), No. (3), 2018, p. $167-175$.

[32] M.M., Diacopoulos, Untangling Web 2.0: Charting Web 2.0 tools, the NCSS guidelines for effective use of technology, and Bloom's Taxonomy. The Social Studies. Vol. (106), No. (4), 2015, p. 139-148.

[33] J.T., Bartels, Soft(a)ware in the English classroom. English Journal. Vol. (106), No. (5), 2017, p. 90-92.

[34] Y. Tang and K.F. Hew, Using Twitter for education: Beneficial or simply a waste of time? Computers and Education. Vol. (106), No. (1), 2017, p. 97-118.

[35] F., Gao., T. Luo, and K. Zhang, Tweeting for learning: A critical analysis of research on microblogging in education published in 20082011. British Journal of Educational Technology. Vol. (43), No. (3), 2012, p. 783-801.

[36] C. Geraths and M. Kennerly, Pinvention: Updating commonplace books for the digital age. Communication Teacher. Vol. (29), No. (3), 2015, p. 116-172.

[37] S., Hu , et al., What do teachers share within socialized knowledge communities: A case of Pinterest. Journal of Professional Capital and Community, 2018. Vol. (3), No. (2), 2018, p. 97-122.

[38] F., Farahmand, The effects of using Viber on Iranian EFL university students' vocabulary learning (an interactionist view). International Journal of Social and Educational Innovation. Vol. (3), No. (5), 2016, p. 31-38.

[39] E., Bagarukayo and B. Kalema, Evaluation of e-learning usage in South African universities: A critical review. International Journal of Education and Development using Information and Communication Technology. Vol. (11), No. (2), 2015, p. 168-183.

[40] G., Grigoraș, D. Dănciulescub, and C. Sitnikovc, Assessment criteria of e-learning environments quality. Procedia Economics and Finance. Vol. (16), 2014, p. 40-46.

[41] L.M. Anstey and G.P.L. Watson, A rubric for evaluating e-learning tools in higher education. EDUCASE Review, 2018: Accessed on 30 January 2020, Available online at https://er.educause. edu/articles/2018/9/arubric-for-evaluating-e-learning-tools-in-higher-education.

[42] M., Meyliana, A.N. Hidayanto, and E.K. Budiardjo, Evaluation of social media channel preference for student engagement improvement in universities using entropy and TOPSIS method. Journal of Industrial Engineering and Management. Vol. (8), No. (5), 2015, p. 1676-1697.

[43] A.D.S. Sirait, et al. Evaluation of social media preference as eparticipation channel for students using fuzzy AHP and TOPSIS. in 2018 4th International Conference on Computing, Engineering, and Design. 2018. Bangkok, Thailand, Bangkok: Institute of Electrical and Electronics Engineers Inc.

[44] C., Hwang and K. Yoon, Multiple Attribute Decision Making. 1 ed. Methods and Applications A State-of-the-Art Survey. 1981, Berlin Heidelberg: Springer, p 58-91
[45] B., Sodhi and T.V. Prabhakar. A Simplified Description of Fuzzy TOPSIS. 2012; Accessed on 30 January 2020; Available from: http://arxiv.org/abs/1205.5098.

[46] R.K., Singh and L. Benyoucef, A fuzzy TOPSIS based approach for esourcing. Engineering Applications of Artificial Intelligence. Vol. (24), No. (3), 2011, p. 437-448.

[47] G., Kannan, S. Pokharel, and P.S. Kumar, A hybrid approach using ISM and fuzzy TOPSIS for the selection of reverse logistics provider. Resources, Conservation and Recycling. Vol. (54), No. (1), 2009, p. 2836.

[48] A., Kelemenis, K. Ergazakis, and D. Askounis, Support managers' selection using an extension of fuzzy TOPSIS. Expert Systems with Applications. Vol. (38), No. (3), 2011, p. 2774-2782.

[49] K., Ayebi-Arthur, E-learning, resilience and change in higher education: Helping a university cope after natural disaster. E-learning and Digital Media. Vol. (14), No. (1), 2017, p. 259-274.

[50] Department of Basic Education. School masterlist data. 2020; Accessed on 30 January 2020; Available from: https://www.education. gov.za/Programmes/EMIS/ EMISDownloads.aspx.

[51] U ., Sekaran and R.J. Bougie, Research Methods for Business: A Skill Building Approach. 7th ed. 2016, Chichester, West Sussex: John Wiley and Sons.

[52] J.E., Fincham, Response rates and responsiveness for surveys, standards, and the journal. American Journal of Pharmaceutical Education. Vol. (72), No. (2), 2008, p. 1-3.

[53] H., Han and S. Trimi, A fuzzy TOPSIS method for performance evaluation of reverse logistics in social commerce platforms. Expert Systems with Applications. Vol. (103), No. (1), 2018, p. 133-145.

[54] W., Huang, et al., Applying fuzzy technique for order preference by similarity to ideal solution (TOPSIS) in the slection of best candidate: A case study on interview performance. British Journal of Economics, Finance and Management Sciences. Vol. (17), No. (1), 2020, p. 36-49.

[55] MathWorks. MATLAB. 2020; Accessed on 30 January 2020; Available from: https://www.mathworks.com/ products/ matlab.html.

[56] HelloYes. Digital statistics and usage in South Africa 2020. 2020; Accessed on 30 January 2020; Available from: https://www. helloyes.co.za/digital-statistics-and-usage-in-south-africa-in-2020/.

[57] SmartInsights. Global social media research summary. 2020; Accessed on 30 January 2020; Available from: https://www.smartinsights. com/social-media-marketing/social-media-strategy/new-global-socialmedia-research/.

[58] K., Husain, et al., Benefits of YouTube videos usage in students' learning. Journal of Human Capital Development. Vol. (5), No. (2), 2012, p. 1-8.

[59] Learn From Blogs. Why YouTube is important for teachers and students. 2021; Accessed on 30 January 2020; Available from: https://learnfromblogs.com/why-youtube-is-important-for-teachers-andstudents.

[60] A., Chand, and Chand, P., Advantages and disadvantages of using Viber as distance student learning tool in a regional university. International Journal of Instructional Technology and Distance Learning. Vol. (14), No. (12), 2017, p. 54-60. 